\title{
Stage II Nasopharyngeal Undifferentiated Carcinoma AJCC v7
}

National Cancer Institute

\section{Source}

National Cancer Institute. Stage I/ Nasopharyngeal Undifferentiated Carcinoma A/CC v7. NCl Thesaurus. Code C8225.

Stage II includes: (T1, N1, M0); (T2, N0, M0); (T2, N1, M0). T1: Nasopharyngeal cancer with tumor confined to the nasopharynx, or tumor extending to oropharynx and/or nasal cavity without parapharyngeal extension. Parapharyngeal extension denotes posterolateral infiltration of tumor. T2: Nasopharyngeal cancer with parapharyngeal extension. Parapharyngeal extension denotes posterolateral infiltration of tumor. N0: No regional lymph node metastasis. N1: Nasopharyngeal cancer with unilateral metastasis in cervical lymph node(s), $6 \mathrm{~cm}$ or less in greatest dimension, above the supraclavicular fossa, and/or unilateral or bilateral, retropharyngeal lymph nodes, $6 \mathrm{~cm}$ or less in greatest dimension. Midline nodes are considered ipsilateral nodes. M0: No distant metastasis. (AJCC 7th ed.) 